\title{
Immigration and transition: Changing demographics forecast the emerging trends in spina bifida care
}

\author{
Jonathan Castillo ${ }^{\mathrm{a}}$ and Timothy J. Brei ${ }^{\mathrm{b}}$ \\ ${ }^{a}$ Developmental Pediatrics, Department of Pediatrics, Meyer Center, Texas Children's Hospital/Baylor College of \\ Medicine, Houston, TX, USA \\ ${ }^{\mathrm{b}}$ Division of Developmental Medicine, Department of Pediatrics, Seattle Children's Hospital and the University of \\ Washington School of Medicine, Seattle, WA, USA
}

\begin{abstract}
Globally, the number of immigrants, refugees, and internally displaced persons is escalating. While immigration is often a result of social determinants, including political discrimination, poverty, education, and work-related prospects, immigration itself can also be conceptualized as a social determinant of health. Through the National Spina Bifida Patient Registry (NSBPR), investigators have begun to recognize existing disparities within growing minority populations affected by spina bifida. Concurrently these individuals are also living longer, therefore, these demographic shifts in age and ethnicity give rise to the dawn of a new era in care. Thus, a call has gone out for multicenter learning collaboratives to face these newfound challenges. An example of such emergent learning collaboratives is the American Academy of Pediatrics (AAP) Spina Bifida Transition Project, sponsored by the CDC, an approach in accordance with the recently published Guidelines for the Care of People with Spina Bifida. Henceforth, it can also be trusted that related original research published in JPRM will continue to serve as a catalyst for culturally-competent investigation and comparative analysis to improve care worldwide.
\end{abstract}

Keywords: Learning collaborative, health disparities, immigrant health, minority health, social determinants of health, globalization/immigration, quality of life, continuum of care transition

\section{Introduction}

Globally, the number of immigrants, refugees, and internally displaced persons is escalating [1]. The US, which is home to more than 43 million immigrants, has the largest number worldwide [2]. While immigration is often a result of social determinants including political discrimination, poverty, education, and workrelated prospects, immigration itself can also be conceptualized as a social determinant of health [3]. Mexico, El Salvador, Cuba, and the Dominican Republic are among the list of countries from where most immigrants become naturalized US citizens [4]. Thus, the estimated 55 million Hispanics/Latinos living in the US are the fastest-growing demographic group [5].
Even as Hispanics/Latinos immigrate into the US, they consistently demonstrate a higher birth prevalence of neural tube defects compared with other racial/ethnic groups [6]. Through the National Spina Bifida Patient Registry (NSBPR), a registry sponsored by the Centers for Disease Control and Prevention (CDC) which has enrolled thousands of individuals across the nation, investigators have begun to recognize existing disparities within this minority population [7].

At the same time that the number of immigrants is growing, individuals affected by spina bifida (SB) in the US are also living longer [8]. It is estimated that there are now more adults then children living with SB [9]. Furthermore, the assessment of SB-related disease burden on their quality of life has become essen- 
tial in culturally competent care across the lifespan. Documenting a paucity of studies and attesting that no firm conclusions could be drawn, a recent Cochrane review recognized that there is some emerging evidence that transition into adult-centered programs improve individuals' knowledge of their condition and their self-efficacy [10]. However, it is also evident that there remains significant space for rigorous evaluation of models of developmentally-appropriate transitional care and long-term follow-up investigating their outcomes. Consequently, these demographic shifts in age and ethnicity give rise to the dawn of a new era in SB care. In this new age, clinicians must not only care for a more diverse patient population, but also for an aging one. Fortunately, clinicians and investigators are rising to the challenges and opportunities this dawning day brings.

Therefore, a call has gone out for multicenter learning collaboratives to face these newfound challenges [11]. An example of such emergent learning collaboratives is the American Academy of Pediatrics (AAP) Spina Bifida Transition Project, also sponsored by the CDC. The AAP, in collaboration with the Spina Bifida Association, has recruited nine pediatric and adult provider practice team pairs to participate in this quality improvement project focusing on transition coordination from pediatric to adult-focused care for individuals living with SB. This collaborative not only aims to addresses transition related issues, but also to do so in a culturally sensitive manner. This approach is in accordance with the Guidelines for the Care of People with Spina Bifida recently published by the Spina Bifida Association (available at: spinabifidaassociation.org/guidelines). To complete these guidelines, comprised of 25 areas of care delivery, the SBA brought together working groups consisting of international, multidisciplinary teams of clinical and research experts [12].

Henceforth, recent care guidelines and innovative studies on prenatal repair, quality of life, and transitions across the lifespan thrust SB-related care into this new era of dynamic and prolific inquiry among an international community of clinicians and investigators. Of this global community, 23 countries were represented by those who participated in the Third World Congress of Spina Bifida Research and Care in 2017. Since that time, the Journal of Pediatric Rehabilitation Medicine (JPRM) has emerged as a global platform for the publication and dissemination of SB-related research. Through this $3^{\text {rd }}$ special issue on SB care, research provides innovative new studies on transition and minority health-related investigation.
It can be trusted that the commentaries and original research published in JPRM will continue to serve as a catalyst for culturally-competent research, as well as thoughtful investigation and comparative analysis of management practices in order to improve the care among the diverse and aging community of individuals affected with SB around the world.

\section{References}

[1] United Nations Office of the High Commissioner for Refugees. Global Trends: Forced Displacement in 2015. Geneva, Switzerland: United Nations Office of the High Commissioner for Refugees, 2016.

[2] Migration Policy Institute. Immigrant profiles and demographics. US data. Available from: https://www.migration policy.org/topics/us-data.

[3] Castañeda H, Holmes SM, Madrigal DS, Young M-ED, Beyeler N, Quesada J. Immigration as a social determinant of health. Annu Rev Public Health. 2015; 36; 375-92. doi: 10.1146/annurev-publhealth-032013-182419.

[4] Zong J, Batalova BM. Frequently requested statistics on immigrants and immigration in the United States. Migration Policy Institute; 2019. Available from: https://www.migration policy.org/article/frequently-requested-statistics-immigrantsand-immigration-united-states

[5] Bureau of the Census UD of C. US Census Bureau projections show a slower growing, older, more diverse nation a half century from now. [Internet]. December 12, 2012. Available from: https://www.census.gov/newsroom/releases/ archives/population/cb12-243.html.

[6] Williams J, Mai CT, Mulinare J, Isenburg J, Flood TJ, Ethen $\mathrm{M}$, et al. Updated estimates of neural tube defects prevented by mandatory folic acid fortification - United States, 19952011. MMWR Morb Mortal Wkly Rep [Internet]. 2015; 64(1): 1-5. doi: mm6401a4 [pii].

[7] Castillo J, Lupo J, Tu D, Agopian A, Castillo H. The National Spina Bifida Patient Registry: A decade's journey. Birth Defects Res. 2018; e1407. doi: 10.1002/bdr2.1407.

[8] Bowman RM, McLone DG, Grant JA, Tomita T, Ito JA. Spina bifida outcome: A 25-year prospective. Pediatr Neurosurg. 2001 Mar; 34(3): 114-20. doi: 10.1159/000056005.

[9] Brei T, Houtrow A. Spina bifida. J Pediatr Rehabil Med. 2017; 10(3-4): 165-166. doi: 10.3233/PRM-170469.

[10] Campbell F, Biggs K, Aldiss SK, O’Neill fnmsPM, Clowes $\mathrm{M}$, McDonagh $\mathrm{J}$, et al. Transition of care for adolescents from paediatric services to adult health services. Cochrane Database Syst Rev. 2016; 4: CD009794. doi: 10.1002/14651 858.CD009794.pub2.

[11] Castillo J. Social determinants of health and spina bifida care: Immigrant and minority health in an era of quality of life and multicenter comparative analysis. J Pediatr Rehabil Med. 2018; 11(4): 213-216. doi: 10.3233/PRM-180484.

[12] Dicianno BE, Beierwaltes P, Dosa N, Raman L, Chelliah J, Struwe S, et al. Scientific methodology of the development of the guidelines for the care of people with spina bifida: an initiative of the spina bifida association. Disabil Health J. 2019; pii: S1936-6574(19)30106-2. doi: 10.1016/j.dhjo.2019. 06.005 . 